\title{
Regulation of hypothalamic NPY by diet and smoking
}

Hui Chen a, Michelle J Hansen ${ }^{\text {a, b }}$, Jessica E Jones ${ }^{\text {a, b }}$, Ross Vlahos ${ }^{\text {a, b }}$, Steve Bozinovski ${ }^{\text {a, b }}$, Gary P Anderson ${ }^{\text {a, b, c }}$, Margaret J Morris ${ }^{\text {a, d }}$

a. Department of Pharmacology, The University of Melbourne, Victoria 3010 Australia.

b. CRC for Chronic Inflammatory Diseases, The University of Melbourne, Victoria 3010 Australia.

c. Department of Medicine, The University of Melbourne, Royal Melbourne Hospital, Victoria 3050 Australia.

d. Department of Physiology \& Pharmacology, School of Medical Sciences, University of New South Wales, NSW 2052 Australia.

Corresponding author:

Professor Margaret J Morris

Department of Physiology \& Pharmacology

School of Medical Sciences

University of New South Wales

NSW 2052, Australia.

Telephone: 61293851560

Fax: 61293851059

Email: m.morris@unsw.edu.au.

Key words: obesity, leptin, cigarette smoke exposure 


\begin{abstract}
Appetite is regulated by a number of hypothalamic neuropeptides including neuropeptide $\mathrm{Y}$ (NPY), a powerful feeding stimulator that responds to feeding status, and drugs such as nicotine and cannabis. There is debate regarding the extent of the influence of obesity on hypothalamic NPY. We measured hypothalamic NPY in male Sprague-Dawley rats after short or long term exposure to cafeteria-style high fat diet (32\% energy as fat) or laboratory chow (12\% fat). Caloric intake and body weight were increased in the high fat diet group, and brown fat and white fat masses were significantly increased after 2 weeks. Hypothalamic NPY concentration was only significantly decreased after long term consumption of the high fat diet.
\end{abstract}

Nicotine decreases food intake and body weight, with conflicting effects on hypothalamic NPY reported. Body weight, plasma hormones, and brain NPY were investigated in male Balb/c mice exposed to cigarette smoke for 4 days, 4 and 12 weeks. Food intake was significantly decreased by smoke exposure (2.32 \pm 0.03 vs. $2.71 \pm 0.04 \mathrm{~g} / 24 \mathrm{~h}$ in control mice (non-smoke exposed) at 12 weeks). Relative to control mice, smoke exposure led to greater weight loss, while pair-feeding the equivalent amount of chow caused an intermediate weight loss. Chronic smoke exposure, but not pair-feeding, was associated with decreased hypothalamic NPY concentration, suggesting an inhibitory effect of cigarette smoking on brain NPY levels. Thus, consumption of a high fat diet and smoke exposure reprogram hypothalamic NPY. Reduced NPY may contribute to the anorexic effect of smoke exposure. 


\section{Appetite regulation and neuropeptide Y (NPY)}

Appetite is regulated by a well designed homeostatic network comprising central and peripheral components that maintain the balance between energy intake and energy expenditure [48,65]. The brain plays a critical role in the regulation of energy homeostasis. Circuits in the central nervous system (CNS) assess and integrate peripheral metabolic, endocrine, and neuronal signals that reflect current energy status, influencing orexigenic and anorexigenic signals to allow adequate energy balance [49]. Therefore despite considerable daily variation in both energy intake and expenditure, most animals including humans maintain a steady body weight for long periods. The hypothalamus is considered the main integrator and processor of peripheral metabolic information, and this region contains many neurotransmitters that stimulate and inhibit appetite.

NPY, a 36 amino acid peptide first isolated in 1982 from porcine brain, is a member of the pancreatic polypeptide family, abundant throughout the CNS [5,52]. Centrally, NPY is a powerful neurochemical stimulator of feeding in many species $[27,43,56]$. NPY levels reflect the nutritional status of the body, contributing to the long term regulation of energy homeostasis. The arcuate nucleus (Arc) is a major hypothalamic site of NPY expression [40]. NPY neurons in the Arc project to the paraventricular nucleus (PVN) to release NPY thus stimulating feeding. Repeated administration of NPY into the hypothalamus induces hyperphagia even under conditions of satiation, decreases energy expenditure, and increases fat deposition promoting weight gain and obesity $[10,20,43]$.

NPY may function as an orexigenic signal regulating periodic eating behaviour. Hypothalamic NPY concentrations are elevated before the introduction of food, and decreased significantly during the course of eating [34]. Expression of NPY mRNA is increased in response to fasting or chronic food restriction, and decreased within 6-24 hours of ad libitum refeeding [6,12,51]. The feeding effects of NPY are mediated by a combination of receptors, with the orexigenic effect being primarily mediated through $\mathrm{Y}_{1}$ and $\mathrm{Y}_{5}$ receptors $[13,33,66]$. Circulating hormones, such as leptin and insulin, can inhibit the anabolic NPY system [1,2,50], while ghrelin, released from the stomach, can stimulate the activity of hypothalamic neurons expressing NPY [60].

\section{States of overnourishment and undernourishment}


The outcome of an extended period of positive energy balance is overnutrition, characterized by excess accumulation of fat. Throughout the world the prevalence of overweight or obesity is increasing, and this disorder has been called a modern "epidemic”, with 1 billion adults overweight, and at least 300 million of them obese [62]. Obesity rates have risen three-fold or more since 1980 not only in western countries, but in eastern Europe, the Middle East, Pacific islands, and China [62]. Childhood obesity is also rising at an alarming rate worldwide. In the USA, the number of overweight children has doubled and the number of overweight adolescents has tripled since 1980 [62]. Overweight and obesity are predisposing factors for diet related chronic diseases, such as type 2 diabetes, hypertension, and coronary heart disease.

While obesity is an emerging problem, cigarette smoking is a long-standing health issue worldwide. Globally about one third of male adults and one in five teenagers smoke. Smoking-related diseases threaten the life of one in ten adults. If the current trend continues, this is predicted to increase to one in six by 2030 [61]. Smokers weigh less than non-smokers of the same age and gender [4,36]. Anorexia often occurs with cigarette smoking [42], and this has also been demonstrated in animals [57]. Suppression of appetite is one of the major motives for smoking, especially among the young and in women [3,4,36,42].

\section{Modeling dietary obesity}

The reasons for the worldwide increase in obesity are hotly debated. Genetically obese animals, such as the obese $o b / o b$ mouse and diabetic $d b / d b$ mouse, have been thoroughly studied to investigate the link between NPY and the etiology of obesity $[31,47,64,67]$. However, genetic mutations only account for a small portion of human obesity. Consumption of sugar-sweetened soft drinks and fast-food intake predicts a weight gain of about $0.4 \mathrm{~kg}$ per year independent of energy intake, physical activity, and television viewing [8]. Diet-induced obesity is a model that may be a better representation of the physiological changes in response to diet related obesity in humans than the genetically obese animal models [39]. In order to investigate the link between brain NPY levels and dietary obesity, our laboratory has developed a palatable high fat diet for rodents that can be applied in young adulthood, allowing us to examine brain NPY peptide level and physiological changes during the development of obesity [26,27,41]. 
Young adult (5-6 week-old) weight-matched (200 g) groups of male Sprague-Dawley rats received standard chow (12\% calories as fat) or a highly palatable cafeteria-style diet (consisting of supplemented chow, meat pies, pasta and cakes, 32\% calories as fat) [26]. Animals can be followed for various periods of dietary intervention, from 2 to 20 weeks $[26,27]$. The caloric intake of the animals on the high fat diet was maintained at $160-196 \%$ that of the chow fed control animals [27]. Body weight, fat mass and plasma leptin concentration increase soon after exposure to the high fat diet [26]. At 2 weeks, when a body weight change was not obvious, both white and brown fat masses had nearly doubled in the animals on a high fat diet [27]. As a result, the level of the adipose-derived hormone leptin was doubled in plasma, and this was maintained after 17 [27] and 20 weeks [26] of diet. At 17 weeks, the body weight of the high-fat diet fed rats was $26 \%$ greater than chow fed control animals [27]. However, hypothalamic NPY peptide concentration measured by radioimmunoassay only decreased with chronic high-fat feeding, including the preoptic and anterior hypothalamus, Arc, and PVN (Table 1) [27]. These changes may be a physiological response to elevated plasma leptin levels or an adaptive response to prolonged enhanced caloric intake [27]. We observed a significant negative correlation between total hypothalamic NPY and plasma leptin concentration. We have observed similar reductions in hypothalamic NPY levels using this dietary model in the mouse, with more pronounced changes in the Arc (35\% reduction) and a similar level of reduction in the PVN as in the rat after 10 weeks of diet, with an 8 fold increase in plasma leptin concentrations [17]. Subsequent studies in our dietary obese rats also revealed hypersensitivity to exogenous NPY injection compared with chow fed control animals [27].

The reduced hypothalamic NPY peptide in the animals on a high fat diet contrasts with the observations in genetically obese animals, such as the $o b / o b$ and agouti mouse, where increased hypothalamic NPY is a major driver of hyperphagia and obesity $[47,53,64]$. Thus, the changes in hypothalamic NPY content in response to dietary intervention are different from genetically obese animals, which highlights the importance of using dietary obese models.

\section{Modeling cigarette smoking}

This body weight and appetite reducing action of smoking appears to be nicotine mediated as indicated by Hajek and colleagues [25]. The effects of nicotine on body weight and caloric intake have been well studied in both humans and animals [7,11,24,25,57]. Cigarette smoke 
contains at least 6000 components that may directly or indirectly affect caloric intake and energy expenditure. Furthermore, smoking exerts an inflammatory stimulus on macrophages which brings about the production of inflammatory cytokines, such as tumor necrosis factor $\alpha$ and interleukin 6, which might be an important early event in the development of disease states associated with smoking [22]. These cytokines have been shown to affect appetite regulation and lipid metabolism [14,32,37,54,55]. Therefore, direct study of the effects of cigarette smoke gives a better insight into smoking-related anorexia and weight loss.

In a short term study, young adult Balb/c mice (8 weeks of age) were exposed to the smoke produced from 3 cigarettes, 3 times a day, for 4 consecutive days or sham-exposed (nonsmoke exposure, control group) [18]. Food intake dropped significantly after the first day of cigarette smoke exposure, and over 4 days, it was reduced by 34\% (2.4 vs. 3.6 g/mouse/day in the smoke and sham-exposed control animals, respectively, $\mathrm{p}<0.05)$. Weight loss became evident within 2 days of smoke exposure, and by the end of the experiment (day 5), body weight of the mice exposed to cigarette smoke was $10 \%$ less than the control animals. This was accompanied by significantly reduced brown fat and retroperitoneal white fat masses, and a 34\% reduction in plasma leptin concentration [18]. However, the reduced food intake did not lead to any changes in hypothalamic NPY concentrations over this short time frame.

Uncoupling proteins (UCPs) are mitochondrial carrier proteins, which are able to dissipate the proton gradient of the inner mitochondrial membrane to increase energy expenditure and thermogenesis [19]. This process is closely related to energy metabolism. UCP3 is implicated in the regulation of mitochondrial fatty acid transport and influences basal metabolic rate $[44,46,58]$. UCP3 mRNA expression was increased in the brown fat of the smoke exposed animals, suggesting increased energy expenditure despite their reduced caloric intake, which may contribute to the rapid fat loss in these animals.

The question that arises is whether the lower caloric intake in animals during short term smoke exposure is the main contributor to the reduced body weight in those animals. To answer this question, a pair-fed group was added in another longer term experiment [15]. In the long term study, animals were exposed to a lower dose of cigarette smoke that was generated from 1 cigarette, 3 times a day, 5 days a week for 4 weeks. A group of shamexposed mice was given the same amount of chow consumed by smoke exposed animals in the previous 24 hours (pair-fed), and a control group had ad libitum chow feeding and were 
sham-exposed. Food intake of the animals exposed to smoke was decreased by $31 \%$ after the first day of smoke exposure, and during the 4 week experimental period it was significantly reduced by $19 \%$. The weight gain of animals exposed to cigarette smoke was slower than control sham-exposed animals, resulting in a nearly $10 \%$ lower body weight after 4 weeks of smoke exposure compared with control animals. Equivalent food restriction in the pair-fed group resulted in a 7\% reduction in body weight. As observed in the short term experiment, mice exposed to cigarette smoke had lower fat mass and plasma leptin concentrations, but this was not observed in the pair-fed group. Interestingly, a significant reduction in PVN NPY concentration was observed only in the animals exposed to cigarette smoke, not in the animals on equivalent food restriction (pair-feeding) [15]. Physiologically, low plasma leptin levels due to fat loss and/or low caloric intake could be expected to stimulate hypothalamic NPY production and release to stimulate feeding [1,21,50]. This may represent a direct inhibitory effect of cigarette smoke exposure on the brain NPY pathway, which may in turn contribute to the spontaneously reduced food intake upon smoke exposure. When the smoke exposure period was extended to 12 weeks, an increase in hypothalamic NPY was observed in the pair-fed animals, which was significantly suppressed by smoke exposure [16]. Relative to sham-exposed control animals, UCP1 and UCP3 mRNA expression was reduced in animals on food restriction, but was preserved in the smoke exposed animals after 4 weeks of smoke exposure [15], suggesting cigarette smoke exposure encourages energy expenditure despite reduced caloric intake.

\section{Why is a decreased hypothalamic NPY observed in these different dietary states?}

In both dietary obesity and cigarette smoking models, hypothalamic NPY concentrations were reduced in the face of two opposite feeding behaviours, hyperphagia and hypophagia. The question raised here is why reductions in hypothalamic NPY happened in two contrasting nutritional states.

In the cigarette smoke exposure model, there appears to be direct inhibitory effects of nicotine or other elements in cigarette smoke on hypothalamic NPY peptide level. Although the decreased NPY peptide levels can potentially upregulate NPY receptor expression, hypothalamic NPY $Y_{1}$ receptor density has been observed to be reduced by chronic nicotine treatment [35]. Therefore, reduced peptide level as well as receptor density may directly contribute to the altered feeding behaviour. 
In the diet-induced obese animals, the reduced hypothalamic NPY concentration would be expected to reduce caloric intake. However, as observed in different experiments using the same diet in our laboratory, hyperphagia was maintained throughout the experimental period. One explanation is that lower endogenous agonist concentration may lead to a possible increase in receptor expression. This was suggested by experiments administering exogenous NPY to dietary obese animals [27]. In previous studies, an increase in receptor expression and binding in the hypothalamus was observed in diet-induced obese animals [30,63], although this was not measured in our studies. Therefore, although hypothalamic NPY content appears to be reduced in dietary obese animals, an altered receptor expression may still allow the orexigenic effects of NPY to maintain hyperphagia and promote fat accumulation. It also has been speculated that NPY may only initiate the hyperphagia and is not necessary to maintain the hyperphagic state [9].

Furthermore, NPY is not the only neuropeptide in the CNS that regulates appetite and energy balance. Neurons expressing orexigenic NPY and agouti-related protein (AgRP) cooperate with neurons expressing anorexigenic proopiomelanocortin (POMC) and cocaine- and amphetamine-regulated transcript. An interaction between NPY and $\alpha$-melanocyte stimulating hormone, one of the peptide cleavage products of the POMC molecule, on feeding regulation has been shown in a previous study [28]. When hypothalamic NPY mRNA expression was reduced in response to high-fat diet feeding, AgRP and POMC mRNA were also downregulated [38,59]. This suggests the anorexigenic neurons containing POMC respond synchronously with orexigenic neurons to maintain the harmony between hyperphagic and anorexigenic neuropeptides.

Feeding is not only controlled by homeostatic mechanisms, which theoretically would allow an individual to maintain an ideal body weight. The brain reward system has been identified to reinforce the motives without homeostatic value [45]. Consumption of a palatable high-fat diet may be considered to be an addictive behaviour, and NPY can directly enhance rewards $[23,29]$. Interactions between the lateral hypothalamus and the nucleus accumbens, and between the neurotransmitters dopamine, serotonin and the opioid system most likely play predominant roles [45].

\section{Summary}


The regulation of feeding and the response of hypothalamic NPY to altered feeding states is complex, and it is difficult to draw conclusions based solely on NPY mRNA expression or absolute NPY peptide levels. In dietary obesity, decreased hypothalamic NPY was a physiological response to excess caloric intake. However, the reduced peptide level may upregulate NPY receptor expression, which could compensate and maintain the orexigenic function of NPY even with reduced endogenous NPY. This may explain the sustained hyperphagic state in high-fat diet fed animals in the face of reduced hypothalamic NPY peptide. In contrast, the reduced NPY concentration in the hypothalamus of cigarette smoke exposed mice is likely due to the inhibitory effects of nicotine and other factors in cigarette smoke. Moreover, NPY receptor density in the hypothalamus has been shown to be reduced in response to nicotine injection, which in turn may limit the orexigenic effect of NPY, thus explaining the prolonged anorexia. Therefore, not only the production of NPY in the hypothalamus, but also its receptors and downstream signals, contribute to these altered feeding states. 


\section{References}

[1] Ahima RS, Saper CB, Flier JS, Elmquist JK. Leptin regulation of neuroendocrine systems. Front Neuroendocrinol 2000;21:263-307.

[2] Air EL, Strowski MZ, Benoit SC, Conarello SL, Salituro GM, Guan X-M, et al. Small molecule insulin mimetics reduce food intake and body weight and prevent development of obesity. Nat Med 2002;8:179-83.

[3] Akbartabartoori M, Lean ME, Hankey CR. Relationships between cigarette smoking, body size and body shape. Int J Obes 2005;29:236-43.

[4] Albanes D, Jones DY, Micozzi MS, Mattson ME. Associations between smoking and body weight in the US population: analysis of NHANES II. Am J Public Health 1987;77:439-44.

[5] Allen YS, Adrian TE, Allen JM, Tatemoto K, Crow TJ, Bloom SR, et al. Neuropeptide Y distribution in the rat brain. Science 1983;221:877-9.

[6] Beck B, Jhanwar-Uniyal M, Burlet A, Chapleur-Chateau M, Leibowitz SF, Burlet C. Rapid and localized alterations of neuropeptide $\mathrm{Y}$ in discrete hypothalamic nuclei with feeding status. Brain Res 1990;528:245-9.

[7] Bellinger L, Cepeda-Benito A, Wellman PJ. Meal patterns in male rats during and after intermittent nicotine administration. Pharmacol Biochem Behav 2003;74:495-504.

[8] Bes-Rastrollo M, Sanchez-Villegas A, Gomez-Gracia E, Martinez JA, Pajares RM, Martinez-Gonzalez MA. Predictors of weight gain in a Mediterranean cohort: the Seguimiento Universidad de Navarra Study 1. Am J Clin Nutr 2006;83:362-70.

[9] Bi S, Ladenheim EE, Schwartz GJ, Moran TH. A role for NPY overexpression in the dorsomedial hypothalamus in hyperphagia and obesity of OLETF rats. Am J Physiol Regul Integr Comp Physiol 2001;281:R254-60.

[10] Billington CJ, Briggs JE, Grace M, Levine AS. Effects of intracerebroventricular injection of neuropeptide Y on energy metabolism. Am J Physiol Regul Integr Comp Physiol 1991;260:R321-7.

[11] Bishop C, Parker GC, Coscina DV. Nicotine and its withdrawal alter feeding induced by paraventricular hypothalamic injections of neuropeptide $\mathrm{Y}$ in Sprague-Dawley rats. Psychopharmacology (Berl) 2002;162:265-72.

[12] Brady LS, Smith MA, Gold PW, Herkenham M. Altered expression of hypothalamic neuropeptide mRNAs in food-restricted and food-deprived rats. Neuroendocrinology 1990;52:441-7. 
[13] Broberger C, Landry M, Wong H, Walsh JN, Hokfelt T. Subtypes Y1 and Y2 of the neuropeptide $\mathrm{Y}$ receptor are respectively expressed in pro-opiomelanocortin- and neuropeptide-Y-containing neurons of the rat hypothalamic arcuate nucleus. Neuroendocrinology 1997;66:393-408.

[14] Bullo-Bonet M, Garcia-Lorda P, Lopez-Soriano FJ, Argiles JM, Salas-Salvado J. Tumour necrosis factor, a key role in obesity? FEBS Lett 1999;451:215-9.

[15] Chen H, Hansen MJ, Jones JE, Vlahos R, Bozinovski S, Anderson GP, et al. Cigarette smoke exposure reprograms the hypothalamic neuropeptide $\mathrm{Y}$ axis to promote weight loss. Am J Respir Crit Care Med 2006;173:1248-54.

[16] Chen H, Hansen MJ, Vlahos R, Jones JE, Bozinovski S, Anderson GP, et al. Chronic smoke exposure in mice reduces appetite and differentially reduces hypothalamic NPY compared to pair-feeding [abstract]. Society for Neuroscience, USA. 2005.

[17] Chen H, Morris MJ. Brain neuropeptide Y (NPY) content is reduced by chronic, but not short term, high fat cafeteria diet in mice. Proc. Australian Neuroscience Society 2005:205.

[18] Chen H, Vlahos R, Bozinovski S, Jones J, Anderson GP, Morris MJ. Effect of shortterm cigarette smoke exposure on body weight, appetite and brain neuropeptide y in mice. Neuropsychopharmacology 2005;30:713-9.

[19] Dalgaard LT, Pedersen O. Uncoupling proteins: functional characteristics and role in the pathogenesis of obesity and Type II diabetes. Diabetologia. 2001;44:946-65.

[20] Egawa M, Yoshimatsu H, Bray GA. Neuropeptide Y suppresses sympathetic activity to interscapular brown adipose tissue in rats. Am J Physiol 1991;260:R328-34.

[21] Elias CF, Aschkenasi C, Lee C, Kelly J, Ahima RS, Bjorbaek C, et al. Leptin differentially regulates NPY and POMC neurons projecting to the lateral hypothalamic area. Neuron 1999;23:775-86.

[22] Fernandez-Real JM, Broch M, Vendrell J, Ricart W. Smoking, fat mass and activation of the tumor necrosis factor-alpha pathway. Int J Obes Relat Metab Disord. 2003;27:15526.

[23] Flood JF, Morley JE. Increased food intake by neuropeptide $Y$ is due to an increased motivation to eat. Peptides 1991;12:1329-32.

[24] Grunberg NE, Bowen DJ, Winders SE. Effects of nicotine on body weight and food consumption in female rats. Psychopharmacology (Berl). 1986;90:101-5.

[25] Hajek P, Jackson P, Belcher M. Long-term use of nicotine chewing gum. Occurrence, determinants, and effect on weight gain. JAMA 1988;260:1593-6. 
[26] Hansen MJ, Ball MJ, Morris MJ. Enhanced inhibitory feeding response to alphamelanocyte stimulating hormone in the diet-induced obese rat. Brain Res 2001;892:1307.

[27] Hansen MJ, Jovanovska V, Morris MJ. Adaptive responses in hypothalamic neuropeptide $\mathrm{Y}$ in the face of prolonged high-fat feeding in the rat. $\mathrm{J}$ Neurochem 2004;88:909-16.

[28] Hansen MJ, Morris MJ. Evidence for an interaction between neuropeptide $Y$ and the melanocortin-4 receptor on feeding in the rat. Neuropharmacology 2002;42:792-7.

[29] Heilig M, Soderpalm B, Engel JA, Widerlov E. Centrally administered neuropeptide Y (NPY) produces anxiolytic-like effects in animal anxiety models. Psychopharmacology (Berl) 1989;98:524-9.

[30] Huang XF, Han M, Storlien LH. The level of NPY receptor mRNA expression in dietinduced obese and resistant mice. Brain Res Mol Brain Res 2003;115:21-8.

[31] Jang M, Romsos DR. Neuropeptide $Y$ and corticotropin-releasing hormone concentrations within specific hypothalamic regions of lean but not $o b / o b$ mice respond to food-deprivation and refeeding. J Nutr 1998;128:2520-5.

[32] Jansson JO, Wallenius K, Wernstedt I, Ohlsson C, Dickson SL, Wallenius V. On the site and mechanism of action of the anti-obesity effects of interleukin-6. Growth Horm IGF Res 2003;13 Suppl A:S28-32.

[33] Kalra SP, Dube MG, Fournier A, Kalra PS. Structure-function analysis of stimulation of food intake by neuropeptide Y: effects of receptor agonists. Physiol Behav 1991;50:5-9.

[34] Kalra SP, Dube MG, Sahu A, Phelps CP, Kalra PS. Neuropeptide Y secretion increases in the paraventricular nucleus in association with increased appetite for food. Proc Natl Acad Sci USA 1991;88:10931-5.

[35] Kane JK, Parker SL, Li MD. Hypothalamic orexin-A binding sites are downregulated by chronic nicotine treatment in the rat. Neurosci Lett 2001;298:1-4.

[36] Klesges RC, Meyers AW, Klesges LM, La Vasque ME. Smoking, body weight, and their effects on smoking behavior: a comprehensive review of the literature. Psychol Bull 1989;106:204-30.

[37] Langhans W, Hrupka B. Interleukins and tumor necrosis factor as inhibitors of food intake. Neuropeptides 1999;33:415-24.

[38] Lin S, Storlien LH, Huang XF. Leptin receptor, NPY, POMC mRNA expression in the diet-induced obese mouse brain. Brain Res 2000;875:89-95. 
[39] Moraes R, Blondet A, Birkenkamp-Demtroeder K, Tirard J, Orntoft T, Gertler A, et al. Study of the alteration of gene expression in adipose tissue of diet-induced obesity (DIO) mice by microarray and RT-PCR analyses. Endocrinology 2003;144:4773-82.

[40] Morris BJ. Neuronal localisation of neuropeptide $\mathrm{Y}$ gene expression in rat brain. J Comparative Neurology 1989;290:358-68.

[41] Morris MJ, Velkoska E, Cole TJ. Central and peripheral contributions to obesityassociated hypertension: impact of early overnourishment. Exp Physiol 2005;90:697702.

[42] Perkins KA. Effects of tobacco smoking on caloric intake. Br J Addict 1992;87:193-205.

[43] Raposinho P, Pierroz DD, Broqua P, White RB, Pedrazzini T, Aubert ML. Chronic administration of neuropeptide $\mathrm{Y}$ into the lateral ventricle of C57BL/6J male mice produces an obesity syndrome including hyperphagia, hyperleptinemia, insulin resistance, and hypogonadism. Mol Cell Endocrinol 2001;185:195-204.

[44] Samec S, Seydoux J, Dulloo AG. Role of UCP homologues in skeletal muscles and brown adipose tissue: mediators of thermogenesis or regulators of lipids as fuel substrate? FASEB J 1998;12:715-24.

[45] Saper CB, Chou TC, Elmquist JK. The need to feed: homeostatic and hedonic control of eating. Neuron 2002;36:199-211.

[46] Schrauwen P, Hesselink M. Uncoupling protein 3 and physical activity: the role of uncoupling protein 3 in energy metabolism revisited. Proc Nutr Soc 2003;62:635-43.

[47] Schwartz MW, Baskin DG, Bukowski TR, Kuijper JL, Foster D, Lasser G, et al. Specificity of leptin action on elevated blood glucose levels and hypothalamic neuropeptide Y gene expression in ob/ob mice. Diabetes 1996;45:531-5.

[48] Schwartz MW, Woods SC, Porte DJ, Seeley RJ, Baskin DG. Central nervous system control of food intake. Nature 2000;404:661-71.

[49] Spiegelman BM, Flier JS. Obesity and the regulation of energy balance. Cell 2001;104:531-43.

[50] Stephens TW, Basinski M, Bristow PK, Bue-Valleskey JM, Burgett SG, Craft L, et al. The role of neuropeptide $\mathrm{Y}$ in the antiobesity action of the obese gene product. Nature 1995;377:530-2.

[51] Swart I, Jahng JW, Overton JM, Houpt TA. Hypothalamic NPY, AGRP, and POMC mRNA responses to leptin and refeeding in mice. Am J Physiol Regul Integr Comp Physiol 2002;283:R1020-6. 
[52] Tatemoto K, Carlquist M, Mutt V. Neuropeptide Y--a novel brain peptide with structural similarities to peptide YY and pancreatic polypeptide. Nature 1982;296:659-60.

[53] Thompson RH, Canteras NS, Swanson LW. Organization of projections from the dorsomedial nucleus of the hypothalamus: a PHA-l study in the rat. J Comp Neurol 1996;376:143-73.

[54] Torti FM, Torti SV, Larrick JW, Ringold GM. Modulation of adipocyte differentiation by tumor necrosis factor and transforming growth factor beta. J Cell Biol 1989;108:1105-13.

[55] Ventre J, Doebber T, Wu M, MacNaul K, Stevens K, Pasparakis M, et al. Targeted disruption of the tumor necrosis factor-alpha gene: metabolic consequences in obese and nonobese mice. Diabetes 1997;46:1526-31.

[56] Vettor R, Zarjevski N, Cusin I, Rohner-Jeanrenaud F, Jeanrenaud B. Induction and reversibility of an obesity syndrome by intracerebroventricular neuropeptide $\mathrm{Y}$ administration to normal rats. Diabetologia 1994;37:1202-8.

[57] Wager-Srdar SA, Levine AS, Morley JE, Hoidal JR, Niewoehner DE. Effects of cigarette smoke and nicotine on feeding and energy. Physiol Behav 1984;32:389-95.

[58] Walder K, Norman R, Hanson R, Schrauwen P, Neverova M, Jenkinson C, et al. Association between uncoupling protein polymorphisms (UCP2-UCP3) and energy metabolism/obesity in Pima indians. Hum Mol Genet 1998;7:1431-5.

[59] Wang H, Storlien LH, Huang XF. Effects of dietary fat types on body fatness, leptin, and ARC leptin receptor, NPY, and AgRP mRNA expression. Am J Physiol Endocrinol Metab 2002;282:E1352-9.

[60] Wang L, Saint-Pierre DH, Tache Y. Peripheral ghrelin selectively increases Fos expression in neuropeptide $\mathrm{Y}$ - synthesizing neurons in mouse hypothalamic arcuate nucleus. Neurosci Lett 2002;325:47-51.

[61] WHO. Fact sheets. Available from: http://www.wpro.who.int/media_centre/fact_sheets/fs_20020528.htm. 2002.

[62] WHO. Obesity and overweight. Available from: http://www.who.int/dietphysicalactivity/publications/facts/obesity/en/print.html 2003.

[63] Widdowson PS, Upton R, Henderson L, Buckingham R, Wilson S, Williams G. Reciprocal regional changes in brain NPY receptor density during dietary restriction and dietary-induced obesity in the rat. Brain Res 1997;774:1-10. 
[64] Wilding JP, Gilbey SG, Bailey CJ, Batt RA, Williams G, Ghatei MA, et al. Increased neuropeptide-Y messenger ribonucleic acid (mRNA) and decreased neurotensin mRNA in the hypothalamus of the obese (ob/ob) mouse. Endocrinology 1993;132:1939-44.

[65] Wynne K, Stanley S, McGowan B, Bloom S. Appetite control. J Endocrinol 2005;184:291-318.

[66] Wyss P, Levens N, Stricker-Krongrad A. Stimulation of feeding in lean but not in obese Zucker rats by a selective neuropeptide Y Y5 receptor agonist. Neuroreport 1998;9:2675-7.

[67] Yamamoto Y, Ueta Y, Date Y, Nakazato M, Hara Y, Serino R, et al. Down regulation of the prepro-orexin gene expression in genetically obese mice. Brain Res Mol Brain Res 1999;65:14-22.

Table 1 Effects of diet-induced obesity on body weight, adiposity, and hypothalamic NPY concentration in the rat

\begin{tabular}{lcccc}
\hline & \multicolumn{2}{c}{9 weeks } & \multicolumn{2}{c}{17 weeks } \\
& Control & High-fat diet & Control & High fat-diet \\
& $\mathbf{n = 9}$ & $\mathbf{n = 8}$ & $\mathbf{n = 1 6}$ & $\mathbf{n = 1 7}$ \\
\hline Body weight (g) & $568 \pm 45$ & $699 \pm 29 *$ & $637 \pm 12$ & $801 \pm 14$ * \\
RpWAT (g) & $8.2 \pm 1.5$ & $19.1 \pm 3.3 *$ & $9.0 \pm 0.5$ & $19.5 \pm 1.1$ * \\
Arc NPY (ng/mg tissue) & $5.2 \pm 0.4$ & $4.7 \pm 0.3$ & $5.6 \pm 0.5$ & $4.4 \pm 0.3$ * \\
PVN NPY (ng/mg tissue) & $2.2 \pm 0.4$ & $1.8 \pm 0.2$ & $2.2 \pm 0.1$ & $1.7 \pm 0.2$ * \\
\hline
\end{tabular}

Data shown as mean \pm S.E.M. Data were analyzed by Student's unpaired $t$ test. $* \mathrm{p}<0.05$, compared to chow fed animals at the same time point. (Adapted from [25])

Arc: arcuate nucleus; PVN: paraventricular nucleus; RpWAT: retroperitoneal white adipose tissue 